\title{
The Inner Louis Vuitton Circle: Arts-Based Research into Russian Luxury
}

\author{
Svenja Tams ${ }^{1}$ (I) $\cdot$ Brigitte Biehl $^{1}$ (D) $\cdot$ Nikolay Eliseev $^{2,3}$
}

Accepted: 20 July 2021 / Published online: 10 September 2021

(C) The Author(s) 2021

\begin{abstract}
Studying luxury and conspicuous consumption in international settings presents unique challenges. Many aspects of luxury and conspicuous consumption cannot easily be put into words because they involve desires, aesthetics, and emotions, as well as taken-for-granted assumptions about social distinction and inequality. Drawing on Nicolai Eliseev's artistic inquiry into luxury consumption in Russia, this article proposes arts-based inquiry as a suitable method for examining embodied and aesthetic knowing about luxury and conspicuous consumption, in particular in intercultural settings. The article illustrates these ideas through a series of sketches and a final artwork, by which Eliseev inquired into his experiences and tacit knowledge. The artwork incorporates a cut-up Louis Vuitton bag and references to luxury brands such as Cartier, Vertu, and Dom Perignon. The artistic form expresses the dividing effects and emotions of luxury consumption in Russian social and economic life. The article contributes to an understanding of aesthetic creation as both a method of inquiry and also a practice of resistance and innovation in relation to fashion discourses. Thus, it illustrates the potential of arts-based research methods in intercultural studies of luxury, and the social sciences more broadly.
\end{abstract}

Keywords Aesthetics · Arts-based research $\cdot$ Creative methods $\cdot$ Louis Vuitton $\cdot$ Luxury $\cdot$ Russia

\section{Introduction}

While luxury can, at first sight, appear as a unifying aspect of globalization and cosmopolitan elites, people's consumption of luxury can nonetheless vary greatly across cultures (other articles in this issue; Berger 2021). Researchers, seeking to understand luxury and conspicuous consumption across cultures, need to address this challenge. For those having no inside (emic) experience, it is difficult to read the atmospheres, moods, and feelings of luxury in a given culture based on abstract (etic) categories of cross-cultural theory. Likewise,

Svenja Tams

svenja.tams@srh.de

Brigitte Biehl

brigitte.biehl@srh.de

1 School of Popular Arts, SRH Berlin University of Applied Sciences, Potsdamer Strasse 188, 10783 Berlin, Germany

2 Moscow, Russia

3 Berlin, Germany researchers with inside knowledge of a culture can find it difficult to describe the tacit aspects of luxury to outsiders.

To address this challenge, we propose that social science studies of luxury and consumption can be enriched through the adoption of the aesthetic perspective of arts-based methods of inquiry. Arts-based inquiry is gaining attention as a result of the performative turn in social sciences and the growing interest in people's lived experiences and emotions (Barry and Meisiek 2010; Meisiek and Barry 2007; Taylor and Ladkin 2009). Arts-based inquiry with visual and material cues, such as colour and fabrics (Rippin 2006), lends itself to areas of social and economic life, which are not fully rational, but driven by emotions, sensual perception, and unconscious patterns of reproducing social distinction and inequality. Thus, an arts-based approach is well suited for an exploration of luxury consumption in international settings, where traditional methods of scientific analysis are insufficient to describe multi-sensory meanings (Meisiek and Barry 2018).

This article develops these ideas based on Nicolai Eliseev's first-hand study of Russian luxury through imagery and aesthetics. The inquiry starts off from experiences of Russian contemporary society where rich people engage in practices of "conspicuous consumption" (Veblen 1899), 
consuming expensive goods to publicly display their economic power, prestige, and status. These social practices manifest consumption symbolically for everyone to see. Thus, they shed light on what social theorists have described as "desires" and strongly aesthetic, emotional, sensual features of consumption (Böhme 2003).

This article contributes to an understanding of the ways by which research methods are entangled with knowledge about luxury. By presenting insights from arts-based inquiry, we broaden beyond the traditional prevalence of economic and sociological approaches. Arts-based inquiry affords an aesthetic lens for strengthening a socially and historically situated understanding of luxury and conspicuous consumption. An arts-based approach strengthens a human-centred perspective, where consumers are not only passive dopes of macro-level social and market forces, but active in the co-construction of their consumption practices and experiences (De Certeau 1988). Furthermore, our inquiry illustrates how Russian luxury is deeply embedded in its post-Soviet history. Thereby, we illustrate how arts-based approaches can illuminate the cultural meanings through which social practices, associated with luxury, are created, maintained, and, possibly, transformed over time.

We organize our argument as follows. First, we develop the notion of arts-based inquiry into luxury, before describing Russian luxury as the empirical context of this article. Then, we present Eliseev's artistic inquiry into Russian luxury. We end with a critical assessment of the potential of arts-based methods for social scientific research about the international aspects of luxury and conspicuous consumption.

\section{Arts-Based Inquiry into Luxury}

An arts-based approach to social science research on luxury and consumption highlights that emotions and aesthetics are of central relevance to luxury, for luxury thrives on abundance, extravagance, and lavishness. At the beginning of the twentieth century, Walter Benjamin in his Arcades Project described the special aesthetic experience of the flâneur in shopping environments, illustrating the beginning of the aestheticization of the commodity world which coincided with the first department stores in Paris. In today's "aesthetic economy", commodities are "given an appearance; they are aestheticized and staged in the sphere of exchange" (Böhme 2003: 72). Böhme (2017) names this the "staging value" of the commodity. Likewise, Veblen (1899) has described the symbolic nature of "conspicuous consumption" that helps to stage life. Furthermore, Pierre Bourdieu ([1979]1984) has argued that consumption serves "distinction" — that is, differentiation from other social groupings. The theory of the aesthetic economy further emphasizes the intensification and emotional nature of consumption, proposing that the aesthetic has become a source of value in its own right. Other theorists, including the sociologist Mike Featherstone (1992) and philosopher Wolfgang Welsch (1997), have identified an "aestheticization" of everyday life, which is about social distinction and also about sensual gratification, bridging many social and emotional dimensions of consumption. In this context, capitalism moves from satisfying people's needs to exploiting their desires. Thus, in late capitalism, producers of luxury create discourses and narratives that elevate these products to objects of desire, rather than appeal to utilitarian rationales (Boltanski and Esquerre 2020). While needs such as hunger can be satisfied through food, "desires" can never be satisfied. The latter require ever more and new luxury items, fashion, and jewellery (Böhme 2017). Desires are created to sell goods to people who have all necessities they need.

While the analysis of text and quantitative data produces explicit knowledge about luxury consumption, an understanding of the desires that drive luxury consumption can benefit from aesthetic ways of knowing. The typical starting point for arts-based research is the creation of an artwork (or other artistic representation) (Meisiek and Barry 2018). Through the embodied process of making the artwork, the creator can access many of the more intricate, emotional, and multilayered aspects of the social discourses in which luxury consumption is embedded. Arts-based research grows from a trust in the intelligence of the creative process of making the artwork. It also explores the relationships among the images that are discernible in the artwork (McNiff 2009). Throughout this process, arts-based inquiry is guided by intuitive, emotional, and embodied ways of knowing - colloquially described as "gut feeling" (Taylor 2002: 828). It is helpful when the inquirer can neither easily articulate their tacit knowing-in-practice nor rationally explain their ideas and the relationship between them (Orlikowski 2002). Here, artistic inquiry picks one idea over another, as long as doing so "feels right".

Thus, artworks transcend the one-to-one relationship between a set of signifiers and the signified. They constitute a whole that is not divisible into its component parts. They are well suited to convey aesthetic, tacit, and embodied forms of knowing (Langer 1942). For example, scholars can say, "I write like a painter", when they produce a scholarly and artistic contribution that defies the common language of academia (Biehl-Missal 2015). In addition, artworks facilitate an ethics of care, a responsible engagement with the world that is represented (Adler 2015). Artworks can make us experience some of the "essence" of a topic, such as luxury. Artworks and the process of their creative production illuminate universally recognized qualities, emotional responses, or ways of being that we do not easily find in conventional research.

Aside from their use in research, arts-based methods are employed in management learning and development (Taylor and Ladkin 2009) and organizational development (Antal et al. 2014; Meisiek and Barry 2007, 2018). Across these 
distinct settings, aesthetic and artistic methods enable participants to integrate their conceptual knowledge about topics such as luxury with personal experiences, and thereby deepen their awareness as actors in an "aesthetic economy" (Böhme 2017). Despite the colourful illustrations in luxury advertising and the appearance of the highly priced items themselves, there is a considerable amount of "aesthetic muteness" (Taylor 2002) around luxury. Popular imagery of luxury conceals issues related to economic power, inequality, the aspirational consumers, and the envy of "the other". While social science theories have extensively discussed social differences and how these translate into taste and consumption (Bourdieu [1979] 1984); Veblen 1899), the emotional elements within the context of an increasingly aesthetic consumption (Boltanski and Esquerre 2020; Böhme 2017) can be addressed with arts-based methods. Arts-based inquiry helps to surface these discourses in society that also are a form of aesthetic knowing (Welsch 1997).

\section{Eliseev's Inquiry into Luxury in Russia}

This section presents the arts-based inquiry of one of the authors of this article, combining sketches, an artwork, and a reflective account. Nicolai Eliseev's artwork and reflections build on his work in design and fashion. Eliseev shall speak in first person from a position that combines creative agency and a lived experience of Russian culture and luxury. He has soaked up its many aesthetic and social dimensions from the inside, but is also able to attain some distance from it through his time spent outside of Russia. The other authors provided guidance and scholarly framing along the way. Biehl provided Eliseev with a Louis Vuitton handbag, which is now part of the artwork. His project explores how people stage their social status through conspicuous consumption and how these processes are strongly aesthetic, addressing the senses and emotions.

Eliseev's account, which follows, illuminates the process of his arts-based inquiry and his substantive insights about luxury in Russia.

The artwork seeks to represent my experiences of Russian luxury. It is informed by qualitative interviews and my own lived experiences (Rippin 2006, 2013). In this project, I set out to do the impossible and describe the concept of Russian luxury in a painting. A lot of the information, which I wanted to interpret, I held already within myself, as tacit or embodied form of knowing. This circumstance made it only harder to pinpoint what information I was looking for exactly.

Having grown up in Russian society, specifically in Moscow, a centre for rich people, I am aware of what luxury feels like in this country, including its mood and atmosphere. There is a shared understanding that the historical development in post-communist Russia led to a separation of rich and poor (Silverman and Yanowitch 2000). A few people bought the former collective means of production, which then provided them and their offspring with a source of effortless income. People often feel that the rich base their wealth on shady, illegitimate, and sometimes even criminal business activities in the past, not having "earned" or deserved it in a meritocratic sense. In this sense, Russia differs from Germany, where a broad middle class is seen to have acquired wealth through honest work during the economic upswing following the second World War (Biehl, 2021). Russians are letting it all hang out and love to present their status through luxury consumption. This can take the form of strong "conspicuous consumption" (Veblen 1899) that is furthered by the aesthetic potential of social media. These aesthetic discourses on social media further the commodity market in late capitalism by providing narrations and valuations of luxury products (Boltanski and Esquerre 2020) that then seem increasingly "desirable". A well-known example is the Instagram account @ richrussiankids with currently 1.8 million followers (\#RRK), where the so-called mazhor (Мажор) (millennial kids of elder wealthy Russians) go shopping at Louis Vuitton, fly private jets, and look down on others. Despite the negative connotation of the sources of wealth, its aesthetics creates a fascination and attraction that draws many young people to brands. I would not exclude myself here. Like other Russians, I feel the "desire" in the aesthetic economy (Böhme 2003), or the so-called fire of desire of consumer passion (Belk et al. 2003).

My arts-based inquiry into the life world of the very rich took several steps. First, I used socio-material storytelling, conducting two interviews with Russian consumers of luxury. I met research participants at their offices to explore which things they consider luxuries and how they participate in the Russian luxury economy. Through these very long conversations, I had all the data in front of me. All I had to do was to structure it for myself.

In a second step, I used sketching. Through sketching (Fig. 1), I was able to put complicated concepts into small images and pinpoint how they could be portrayed to other people. This step in the process provided me with a better understanding of details, such as small connections, history, and unexpected new things that have only recently been adopted by the Russian consumers of luxury.

In a third step, I created the artwork. In this step, I have drawn from previous steps of my research to assemble the details, aesthetics, and colours.

An additional stimulating and thought-provoking part of my inquiry was working with a new material. I was offered a Louis Vuitton bag to use for this artwork (Fig. 2). The bag is a "Pochette" model that the second author has carried with her for about a decade. It can still yield a price of several hundred Euros on second-hand platforms, where luxury 
Fig. 1 Preliminary sketches of Russian luxury consumption (photo: Eliseev)
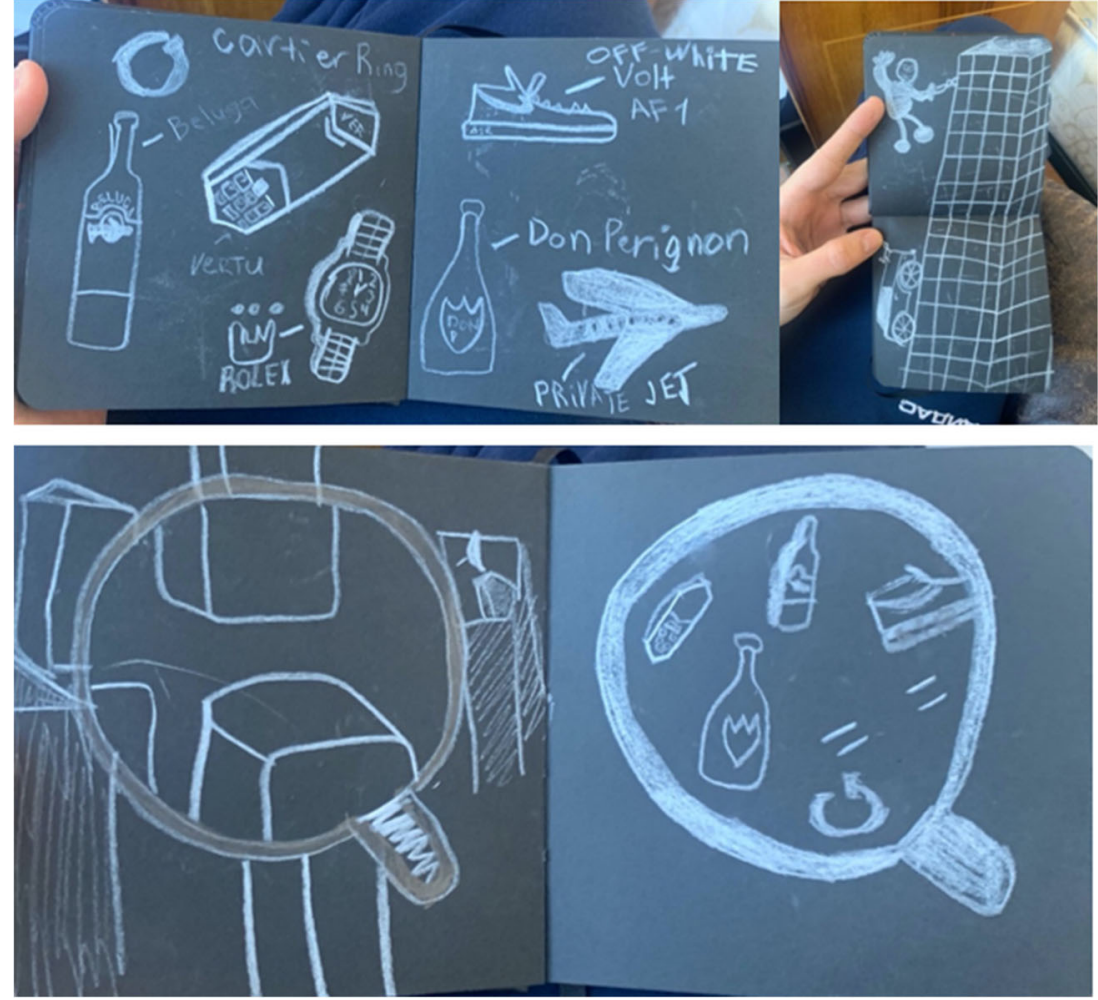

items trickle down society. I was happy to use the leather material, given the role of Louis Vuitton as a status symbol that is ubiquitous among wealthy Russians. From what I have experienced, Russians aim to "send meaningful social signals to other consumers" about themselves as a type of person through their brand choices (Han et al. 2010: 26). As explicated in the literature, Russian luxury consumption strongly revolves around the concept of signalling status through material possessions. Therefore, I used the material

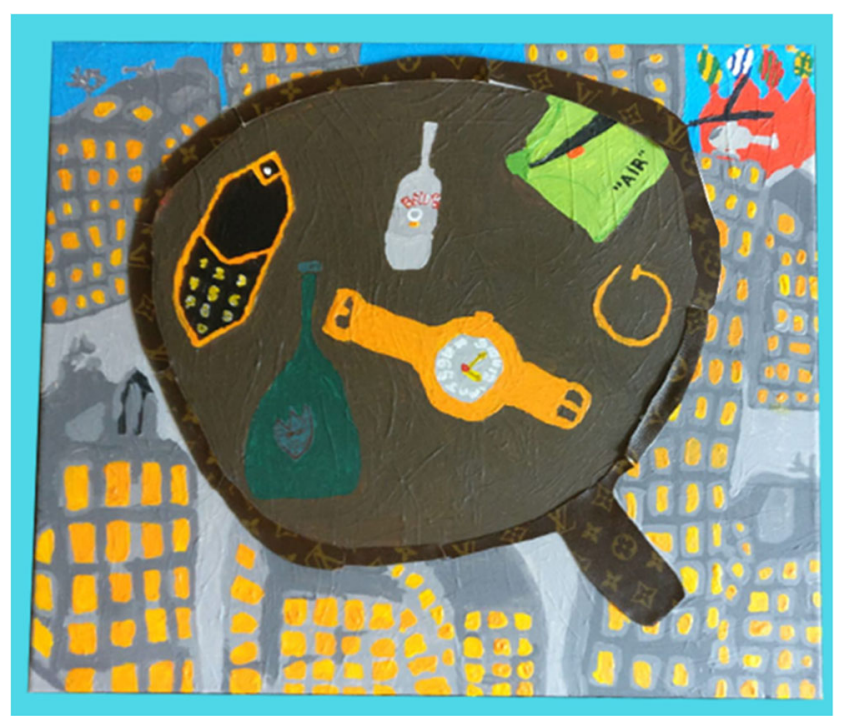

Fig. 2 Final artwork on luxury in Russia (photo: Eliseev) from the bag as both a magnifying glass into the world of the rich, and also as a dividing fence between classes. In the "inner circle" of the Louis Vuitton magnifying glass, we see luxury objects that are items of everyday consumption for those in the upper class.

Outside the Louis Vuitton boundary that represents a magnifying glass, "normal" Moscow is illustrated in its grey colours and with the yellow lights. This is the typical colour of the district heating. It creates an atmosphere that is less sad than it would be without the warmth. It is important that the image does not only signify ideas semiotically but has its specific mood and atmosphere. Thereby, the visual encounter is an aesthetic situation that creates emotions and cognitive interpretations (Biehl-Missal 2013). The artwork in this sense does include indexical signs and points to the social character of elements. For example, a golden object is cognitively linked to "wealth". We also recognize the helicopter as a status symbol and the Saint Basil's Cathedral as a pars-pro-toto for Moscow. At the same time, the artwork conveys the synesthetic character of the elements which appeal to a range of sensual elements, when we perceive a colour as "warm" (Biehl-Missal 2013: 359), or the entire arrangement as something warm, desirable ("fire of desire"), and soothing. Via its mood, the canvas creates emotional effects and cognitive reactions.

The objects in the centre are luxury brands that represent status and class. They include expensive watches and the famous Cartier ring in the form of a nail. The "Juste un Clou" 
design transforms a usual, cheap, utilitarian item - a nail into a piece of jewellery. What has been interpreted by Cartier (2020) as a "creative twist on a familiar object", which "transcends the everyday, making the ordinary exquisite, for him and for her", can also be seen as a social statement of the rich. Unlike the working class, the rich do not touch or work with nails, unless they wear golden or platinum nail-shaped rings, which cost at least a thousand US Dollars. Among the items is also the once widespread Vertu phone, which allowed communications without being tracked. Thus, the Vertu is a device for those who do not want to be traced because they are involved in shady business deals. Here, the imagery points to what is perceived as the shady pedigree of wealthy Russians. The off-white label and rare Nike sportswear are sought for items among the rich. Expensive vodka is also "big" in Russia. Likewise, the pricey Champagne brand "Dom Perignon" is "central" in Russian luxury, as it is consumed en masse by the rich Russians and their kids. As an artist myself, I have negative memories of a classmate in high school opening a bottle of Dom during a normal weeknight, while I barely had enough money to buy myself a bag of crisps for dinner.

Overall, the boundary established by the material of a Louis Vuitton bag serves as a magnifying glass that lets you see things in new ways and shows what you normally do not see. These elements are entrenched in social life of Russian society and separate the rich from the poor. I have experienced many of these elements because I have crossed diverse social circles. With social media, these items gain visibility and show ordinary people elements of life, which historically had not been visible to such an extent, adding to their fascination with the luxury market.

\section{Concluding Thoughts}

Eliseev's account illustrates in several ways that arts-based inquiry lends itself to the study of complex social issues, such as luxury and conspicuous consumption in Russia.

First, Eliseev's arts-based inquiry provides a multi-layered account of the role of luxury and conspicuous consumption in maintaining the historically situated social structure of Russian society. The fascination with ostentatious forms of luxury can on the surface be read as manifestations of the material values characterizing the emerging economy of post-Soviet Russia. Yet, Eliseev's artwork and account also illuminate the role of luxury in maintaining and stabilizing the historical divide between elites and working classes, which can be traced back to pre-Soviet, Tsarist Russia. His use of symbolic imagery in the space outside the boundaries of the looking glass - such as the onion domes of the Russianorthodox cathedral and the warmth of the grey housing complexes - suggests a stability, if not complicity, by those excluded from the Russian wealthy elite's lifestyle of luxury. Thus, in contrast to more distanced methods of social sciences, which may describe social inequalities, we gain an immediate sense of the paradoxical interdependence of the luxury consuming elites and the excluded.

Second and more generally, our study suggests arts-based inquiry as a transdisciplinary, multi-sensory approach for integrating the often unconscious and contradictory emotions surrounding complex social issues (Antal et al. 2014; Barry and Meisiek 2010), such as luxury. This was evident in the arts-based research process that emerged in interactions among the co-authors. Eliseev's account illustrates how artsbased inquiry circles between different ways of knowing emotions, imagery, sensemaking, and playful making. In this process, Eliseev drew on his embodied and aesthetic ways of knowing about his experiences within and outside of rich Russian circles. Eliseev is both an insider and travelling expat to Russian culture. He has access to wealthy circles of Russian society, but also stands outside those circles as a student and designer. He willingly admits to his own fascination with the world of Russian luxury consumption, into which he has been socialized. Rather than attempting the impossible feat of speaking from the position of an objective outsider, the artsbased process enabled Eliseev to step into the emotional and symbolic terrain of Russian luxury culture, while also taking a personal stance on the aesthetic objectification of his multilayered experiences. For Biehl, it was gratifying to see that her well-worn Louis Vuitton bag was transformed into a looking glass, thereby giving new meaning to a luxury item and metaphorically illustrating the potential of arts-based inquiry for a critical lens on social reality. While arts-based methods of inquiry are well-documented in leadership and organizational development, our article also points to the relevance of artsbased methods for qualitative consumer research, in particular in cross-cultural settings.

Third, our study also shows that aesthetic forms of inquiry are not limited to exploring individual subjectivities, but also hold the potential for critical social sciences that resists and seeks to transform mainstream discourses and practices (Biehl-Missal 2015). Thus, arts-based approaches can inquire into the institutionalized emotionality of luxury as a cultural practice and discourse of consumption. In the case of luxury, resistance to and transformation are important. Luxury is not only unsustainable, but also associated with tremendous social and economic power. It rests on global exploitation and environmental destruction. It is socially constructed in glossy ads, upscale establishments, and shiny social media pictures. And yet, our growing awareness of environmental destruction and social inequality invites us to explore sustainable, affordable, and up-cycled ways of consuming. By making his artwork, Eliseev has stepped outside the taken-for-granted meanings, which are shared among the inner circle of his rich friends and acquaintances. His artwork explored marginalized and 
silenced meanings of luxury and thereby created a "richer" perspective on luxury - one that feels more real. Building on this case study, we argue that engaging in personal forms of arts-based inquiry can enable a more critical engagement with the systems and values in which the production and consumption of luxury goods and services are embedded. For example, arts-based inquiry can enable Haute Couture designers to gauge new and innovative forms of self-expression, clothing, and accessories. Thus, arts-based inquiry lends itself to asking ourselves how we want to live in the future.

Funding Open Access funding enabled and organized by Projekt DEAL.

Open Access This article is licensed under a Creative Commons Attribution 4.0 International License, which permits use, sharing, adaptation, distribution and reproduction in any medium or format, as long as you give appropriate credit to the original author(s) and the source, provide a link to the Creative Commons licence, and indicate if changes were made. The images or other third party material in this article are included in the article's Creative Commons licence, unless indicated otherwise in a credit line to the material. If material is not included in the article's Creative Commons licence and your intended use is not permitted by statutory regulation or exceeds the permitted use, you will need to obtain permission directly from the copyright holder. To view a copy of this licence, visit http://creativecommons.org/licenses/by/4.0/.

\section{References}

Adler, N. J. (2015). Finding beauty in a fractured world: Art inspires leaders - leaders change the world. Academy of Management Review 40(3): 480-494.

Antal, A. B., Taylor, S.S., \& Ladkin, D. (2014). "Arts-based interventions and organizational development: It's what you don't see". In Bell, E., Warren, S., \& Schroeder, J. E. (eds.).The Routledge Companion to Visual Organization, 281-292. Routledge.

Barry, D., \& Meisiek, S. (2010). Seeing more and seeing differently: Sensemaking, mindfulness, and the workarts. Organization Studies 31(11): 1505-1530.

Belk, R., Ger, G. and Askegaard, S. (2003). The fire of desire: a multisited inquiry into consumer passion. Journal of Consumer Research 30: 326-351.

Berger, A. A. (2021). Luxury and American Consumer Culture. Cambridge Scholars Publishing. Newcastle upon Tyne.

Biehl, B. (2021) Luxury in Germany: Sick cars and healthy bodies. Society. (forthcoming)

Biehl-Missal, B. (2013). The atmosphere of the image: an aesthetic concept for visual analysis, Consumption Markets \& Culture 16(4): 356-367.

Biehl-Missal, B. (2015). 'I write like a painter': Feminine creation with arts-based methods in organizational research. Gender, Work and Organization 22(2): 179-196.

Böhme, G. (2003). Contribution to the Critique of the Aesthetic Economy. Thesis Eleven 73(1): 71-82.

Böhme, G. (2017). Critique of Aesthetic Capitalism. Berlin: Mimesis International.
Boltanski, L. and Esquerre, A. (2020). Enrichment: A Critique of Commodities, transl. C. Porter. Cambridge: Polity.

Bourdieu, P. ([1979]1984). Distinction. A Social Critique of the Judgment of Taste, transl. R. Nice. Cambridge, MA: Harvard University Press.

Cartier (2020). Website, "Juste un Clou Ring SM" https://www.cartier. com/en-us/collections/jewelry/jewelry-selections/yellowgold-rings$\mathrm{men} / \mathrm{b} 4225900$-juste-un-clou-ring-sm.html (Accessed 18.5.2021)

De Certeau, M. (1988). The Practice of Every Life, transl. S.F. Rendall. Berkeley: University of California Press.

Featherstone, M. (1992). Postmodernism and the Aestheticization of Everyday Life. In Lash, S. \& Friedman, J. (eds.) Modernity and Identity,, 265-290. Oxford: Blackwell.

Han, Y., Nunes, J. and Drèze, X. (2010). Signalling status with luxury goods: the role of brand prominence. Journal of Marketing 74(4): 15-30.

Langer, S. (1942). Philosophy in a New Key. Cambridge, MA: Harvard University Press.

McNiff, S. (2009). Art-based research. In Knowles, J. \& Cole, A (eds.) Handbook of the Arts in Qualitative Research: Perspectives, Methodologies, Examples, and Issues, 29-40. London: Sage.

Meisiek, S., \& Barry, D. (2007). Through the looking glass of organizational theatre: Analogically mediated inquiry in organizations. Organization Studies 28(12): 1805-1827.

Meisiek, S., \& Barry, D. (2018). Finding the sweet spot between art and business in analogically mediated inquiry. Journal of Business Research 85: 476-483.

Orlikowski, W. J. (2002). Knowing in practice: Enacting a collective capability in distributed organizing. Organization Science 13(3): 249-273.

Rippin, A. (2006). Refusing the therapeutic: Marion Milner and me. Culture and Organization 12(1): 25-36.

Rippin, A. (2013). Putting the Bodyshop in its place: A studio-based investigation into the new sites and sights of organization as experience. Organization Studies 34(10): 1551-1562.

Silverman, B. and Yanowitch, M. (2000). New Rich, New Poor, New Russia: Winners and Loser on the Russian Road to Capitalism. London: ME Sharpe.

Taylor, S. (2002). Overcoming aesthetic muteness: Researching organizational members' aesthetic experience. Human Relations 55(7): 821-840.

Taylor, S. S., \& Ladkin, D. (2009). Understanding arts-based methods in managerial development. Academy of Management Learning \& Education 8(1): 55-69.

Veblen, T. (1899). The Theory of the Leisure Class: An Economic Theory of Institutions. New York: Macmillan.

Welsch, W. (1997). Undoing Aesthetics. London: Sage.

Publisher's Note Springer Nature remains neutral with regard to jurisdictional claims in published maps and institutional affiliations.

Svenja Tams $(\mathrm{PhD})$ is Professor of Management, Organizations and Leadership at the School of Popular Arts, SRH Berlin University of Applied Sciences, Germany. She was previously Lecturer/Assistant Professor at the University of Bath School of Management. Her research examines the practices by which management practitioners construe their career and work competences in the context of contemporary knowledge work, including the emerging fields of sustainability management, management consulting, and creative business services. She also studies innovative practices of management learning for social change integrate 
cognitive, embodied, artful, and designerly ways of knowing. Her research has been published in international journals such as Human Relations, Journal of Organizational Behavior, Journal of Vocational Behavior, and Career Development International.svenja.tams@srh.de

Brigitte Biehl (PhD) is Professor of Media and Communication Management at the School of Popular Arts, SRH Berlin University of Applied Sciences, Germany. She is the director of the SRH Institute "Institut für Weiterbildung in der Kreativwirtschaft IWK" that applies experiential learning methods for professional development. She has widely published on aesthetics, marketing, and consumption, and explores creative approaches to management and the influence of popular culture. Her latest books are Leadership in Game of Thrones (Palgrave, 2021) and Management in der Kreativwirtschaft (Springer, 2020). brigitte.biehl@srh.de

Nikolay Eliseev is a Russian artist, designer, and fashion creator from Moscow. Currently he studies in the B.A. Creative Industries Management at the School of Popular Arts, SRH Berlin University of Applied Sciences, Germany. nikolayeliseev98@gmail.com 